\title{
MJN CARING BEHAVIORS AND QUALITY OF CARE RENDERED BY COMMUNITY HEALTH NURSES IN PHILIPPINES
}

\author{
Sheilomay A. Majait, Berna B. Sallave, Pearl Irish V. De Paz* \\ School of Nursing and Health Sciences, Biliran Province State University, Philippines \\ *Corresponding Author's Email: pearlirishvdepaz@gmail.com
}

\begin{abstract}
Introduction: Nursing has been referred as a "caring profession" that requires the practitioner to exhibit and convey the art of caring which has also been the mind setting inculcated among nursing professionals in the community health setting. Hence, the study is aimed to determine the caring behaviors and the quality of nursing care rendered by community health nurses. Methods: The study applied a quantitative correlational-predictive research design. A purposive sampling was employed to identify the 100 respondents who were nurses assigned in the different community healthcare facilities and centers of the different barangays in the Municipality of Biliran, Philippines. The self-administered questionnaires were distributed among the respondents. To analyze the data, descriptive statistics such as mean and weighted mean were used. Likewise, the regression analysis was also used to determine which of the caring factors predicts the quality of care. Results: The seven caring behaviors were highly evident among the community health nurses and a good quality of nursing care was reported. Likewise, all the seven caring behavior predicts the quality of nursing care. Conclusion: The outcome was found to be positive for the overall standard of treatment. The research concluded that the overall level of treatment revealed is predicted by caring behaviors.
\end{abstract}

\section{Keywords: Caring Behaviors; Quality Nursing Care; Community Health Nurses}

\section{INTRODUCTION}

There is a common notion that people often refer to it as a "caring occupation" when it comes to nursing. A profession that helps practitioners to illustrate and express the art of caring. According to Karlsson \& Pennbrant (2020), a common understanding in caring and nursing is needed in nursing practice. In the community health climate, this has been the mind setting inculcated among nursing professionals. While nursing professionals may exhibit higher levels of care than their peers who are training for other professions, they are more likely to exhibit high levels of care. With the call to increase the standards of care among current and future nurses, educators are asked to build new and efficient pedagogies that teach care to nurses. However, it is not a trivial activity to help nurses establish greater standards of treatment. Nurses need a clear and consistent understanding of what caring is, what skills and abilities are necessary to be successful in caring, and how to ensure that they grow to be productive while they practice the profession regularly.

There were five distinctive skilled care principles according to Roach's Theory. This includes compassion, integrity, trust, sense of right and wrong and dedication. This helps to differentiate the concept of expert treatment as being just an emotional reaction to the 
suffering of others or human reaction that would be exhibited by most human beings. Moreover, her theory indicates that compassion is irrelevant in addition to competence in nursing (Roach, 2002). Furthermore, in a phenomenological investigation, metathemes were identified in the use of the individual and group interviews with both sufferers and experienced nurses that recognized customer/patient approaches as important for both patients and nurses. The study conveys nursing as an art and explain the intricate creative processes that nurses and patients undergo (Appleton, 1993).

Compared to being handled in a personcentered manner, they may ably define the difference between being handled in a kindly yet objective manner. As stated earlier, good communication and relationship skills are the fundamental components of treatment that are needed by today's skilled nurses (Sibiya, 2018). Unfortunately, not all nurses have these credentials and are not always seen as compassionate individuals. More alarmingly, there is an evidence that suggest that the quality of treatment of certain nurses significantly declined while in service (Poortaghi, et al., 2019). Therefore, it is important that nurses be assessed on their caring behavior and the quality of care rendered among their patients to be able to craft possible interventions that would improve their nursing practice. However, no study has been written in literature yet that determined the caring behaviors and quality of care rendered by community health nurses specifically in the Province of Biliran, Philippines. Hence, the study was conducted. This study made use of the a predictive-correlational research design to determine the caring behaviors and quality of care rendered by community health nurses assigned in Biliran Province and to determine which caring factors predict the quality of nursing care.

\section{METHODOLOGY}

\section{Study Design}

The study utilized the correlational-predictive research design which made use of two standardized tools for data gathering. This study focused on the assessment of the caring behaviors and the quality of nursing care rendered by selected 100 community health nurses assigned in the barangay health centers in the Municipality of Naval, Biliran, Philippines.
Likewise, it also examined which of the caring factors predicts quality of care.

\section{Respondents}

A total of 100 ccommunity health nurses assigned in the barangay health centers were chosen as the respondents of the study. A purposive sampling was used in the selection of the respondents. The inclusion criteria were the following: (1) Nurses who are in direct patient/client care in barangay health centers including those retained under any non-government program; (2) those who renders service from January 1 to April 30, 2019 in the barangay health centers of the municipality of Naval, Biliran; (3) willing to be part of the study. Those not mentioned in the inclusion criteria are the exclusion criteria.

\section{Instruments}

The first tool used in the study is based on the standardized tool authored by Cronin \& Harrison (1988) that has specific indicators to determine the factors which include humanism/faith-hope/ sensitivity, helping/trust, expression of positive/ negative feelings, teaching/learning, supportive/ protective/ corrective environment, human needs assistance and existential/phenomenological/spiritual. The questionnaire has a 4-Likert scale which has corresponding response category and parameter limit as follows: 1- Never, 2- Seldom, 3- Some of the Time, 4- Most of the Time (Cronin \& Harrison, 1988).

The second tool used in the study is based on the standardized tool by Laschinger et al., (2005) to determine the quality of nursing care rendered by the community health nurses. The said tool has items to measure satisfaction with the overall quality of care by the community health nurses. Each item consists of a phrase to designate the content of the question followed by a more detailed question or "descriptor. The instruments have a 4-Likert scale with sub-parameters which are rated as 4- Very Good; 3-Good, 2- Fair and 1Poor.

\section{Data Gathering Procedure}

The study was conducted with the complete observance of the procedures required by the university in conducting research. The study was conducted in the entire months of January to April 2019. First, a 
transmittal letter was sent to the Municipal Health officer of Naval, Biliran for the permission and approval to conduct the study. After the approval, the list of qualified respondents was obtained from the rural health unit of Naval, Biliran. The informed consents of the respondents were obtained prior to the actual data collection by asking them to sign the informed consent form that suggested the voluntary decision of the respondent to be part of the study after carefully explaining the study and the questionnaire. Likewise, indicated in the procedures of the data collection including the time that the respondents need to consume to complete in answering the questionnaire. The researcher ensured that all respondents were informed as to how they can contact the researcher within a reasonable time period following their participation should stress or potential harm arise. Next, the selfadministered questionnaires were distributed among the participants during their respective work shifts and retrieved after a week. Lastly, the accomplished questionnaires were then processed, analyzed, presented in tabular forms and interpreted.

\section{Data Analysis}

The data on the caring behaviors of the respondents were derived by computing the weighted mean of each caring behavior indicator. After calculating the weighted mean, the average weighted mean was also calculated in order to determine the over-all caring behavior data. The weighted mean and average weighted mean were interpreted using the following scale: 4(3.26-4.0)- Highly Evident; 3(2.51-3.25)Evident; 2(1.76-2.5)-less evident; 1(1.00-1.75)- Not evident.

Moreover, the quality of nursing care was derived by also computing the weighted mean and the average weighted mean. The weighted mean and average weighted mean were interpreted using the following scale: 4(3.26-4.0)- Very Good; 3(2.51-3.25)- Good; 2(1.76-2.5)-Fair; 1(1.00-1.75)- Poor. Furthermore, a regression analysis was done to determine which of the caring behaviors predicts the quality of nursing care.

\section{Ethical Considerations}

Prior to data collection, informed consents were given to the respondents indicating the intent of the research, the possible benefits and damage of the study, maintaining their full privacy during the study, and having the freedom to withdraw from the study at any time $2^{\text {nd }}$ November, 2021. After the distribution of the informed consents, the respondents were asked to sign the informed consent signifying the respondent's voluntary decision to be part of the study. The researcher addressed issues such as confidentiality, anonymity and privacy. Furthermore, the accomplished questionnaires were stored in a safe place and will be shredded or burned after two years.

\section{RESULTS}

\section{Caring Behaviors}

Table 1: Caring Behaviors of Respondents

\begin{tabular}{|l|l|l|c|}
\hline $\begin{array}{l}\text { Predictor } \\
\text { No. }\end{array}$ & Variables & WM & Description \\
\hline 1 & $\begin{array}{l}\text { Humanism/faith- } \\
\text { hope/sensitivity }\end{array}$ & 3.36 & $\begin{array}{c}\text { Highly } \\
\text { Evident }\end{array}$ \\
\hline 2 & Helping/trust & 3.49 & $\begin{array}{c}\text { Highly } \\
\text { Evident }\end{array}$ \\
\hline 3 & $\begin{array}{l}\text { Expression of positive/ } \\
\text { negative feelings }\end{array}$ & 3.26 & $\begin{array}{c}\text { Highly } \\
\text { Evident }\end{array}$ \\
\hline 4 & $\begin{array}{l}\text { Teaching/ learning } \\
\text { Highly } \\
\text { Evident }\end{array}$ \\
\hline 6 & $\begin{array}{l}\text { Supportive/ protective/ } \\
\text { corrective environment }\end{array}$ & 3.44 & $\begin{array}{c}\text { Highly } \\
\text { Evident }\end{array}$ \\
\hline 7 & $\begin{array}{l}\text { Human needs assistance } \\
\text { phenomenological/spiritual }\end{array}$ & 3.83 & $\begin{array}{c}\text { Highly } \\
\text { Evident }\end{array}$ \\
\hline & $\begin{array}{l}\text { Average Weighted mean } \\
\text { Evighly } \\
\text { Evident }\end{array}$ \\
\hline
\end{tabular}

Legend: 4(3.26-4.0)- Highly Evident 3(2.51-3.25)-Evident 2(1.76-2.5)-less evident 1(1.00-1.75)- Not evident

Table 1 presents the data on the level of caring behaviors of the community health nurses or the respondents. It can be seen on the table that based from the seven criteria on caring behaviors, all were rated or interpreted as "Highly Evident". This implies that most of the time, the community health nurses practiced the seven criteria of caring behavior such as humanism/ faith/hope/sensitivity, helping/trust, expression of positive or negative feelings, teaching/learning, supportive/ protective/ corrective environment, human needs assistance, existential/phenomenological/ spiritual. Moreover, results also show that predictor no. 6 or human needs assistance got the highest weighted mean among the seven predictors while predictor no. 7 got the least weighted mean. 


\section{Quality of Nursing Care}

Table 2: Quality of Care

\begin{tabular}{|c|c|c|c|}
\hline No. & Indicator & $\begin{array}{c}\text { Weighted } \\
\text { Mean }\end{array}$ & $\begin{array}{l}\text { Descriptive } \\
\text { Equivalent }\end{array}$ \\
\hline 1 & $\begin{array}{l}\text { Information were } \\
\text { provided: }\end{array}$ & 3.16 & Good \\
\hline 2 & $\begin{array}{l}\text { Ease of information } \\
\text { for getting }\end{array}$ & 3.11 & Good \\
\hline 3 & $\begin{array}{l}\text { Informing family or } \\
\text { friends }\end{array}$ & 3.22 & Good \\
\hline 4 & $\begin{array}{l}\text { Family and friends } \\
\text { involving in your } \\
\text { care }\end{array}$ & 3.21 & Good \\
\hline 5 & $\begin{array}{l}\text { Importance and } \\
\text { caring }\end{array}$ & 3.16 & Good \\
\hline 6 & $\begin{array}{l}\text { Treatment about } \\
\text { your condition }\end{array}$ & 3.21 & Good \\
\hline 7 & $\begin{array}{l}\text { Your views' } \\
\text { recognition }\end{array}$ & 3.43 & Very Good \\
\hline 8 & $\begin{array}{l}\text { Assessment of your } \\
\text { needs }\end{array}$ & 3.21 & Good \\
\hline 9 & The daily schedule & 3.22 & Good \\
\hline 10 & Kindness & 3.37 & Very Good \\
\hline 11 & Answer to your calls & 2.45 & Fair \\
\hline 12 & $\begin{array}{l}\text { Ability and } \\
\text { competence }\end{array}$ & 3.58 & Very Good \\
\hline 13 & $\begin{array}{l}\text { Restfull atmosphere } \\
\text { provided }\end{array}$ & 2.48 & Fair \\
\hline 14 & Confidentiality & 3.21 & Good \\
\hline 15 & Treatment directives & 3.12 & Good \\
\hline 16 & $\begin{array}{l}\text { Coordination of care } \\
\text { after treatment } \\
\text { regimen is } \\
\text { completed }\end{array}$ & 1.89 & Fair \\
\hline & Average mean & 3.06 & Good \\
\hline
\end{tabular}

Legend: 4(3.26-4.0)-Very Good;3(2.51-3.25)-Good; 2(1.76-2.5)-Fair; 1(1.00-1.75)-Poor

Table 2 presents the level of the quality of nursing care provided by the community health nurses. The result revealed that the skills and competence was very good. On the other hand, the coordination of care after treatment rated as the lowest which is interpreted as fair. The average mean was interpreted as good.

\section{Predictors of Quality Nursing Care}

Table 3. Caring Factors that Predict the Quality of Nursing Care

\begin{tabular}{|l|c|c|c|c|}
\hline Variables & R2 & Beta & $\boldsymbol{P}$ & $\begin{array}{c}\text { Significance } \\
\text { level }\end{array}$ \\
\hline $\begin{array}{l}\text { Humanism/faith- } \\
\text { hope/sensitivity }\end{array}$ & 0.439 & 0.553 & 0.00 & $P<0.001$ \\
\hline Helping/trust & 0.453 & 0.548 & 0.00 & $P<0.001$ \\
\hline $\begin{array}{l}\text { Expression of positive/ } \\
\text { negative feelings }\end{array}$ & 0.541 & 0.549 & 0.00 & $P<0.001$ \\
\hline Teaching/ learning & 0.541 & 0.661 & 0.00 & $P<0.001$ \\
\hline $\begin{array}{l}\text { Supportive/ protective/ } \\
\text { corrective } \\
\text { environment }\end{array}$ & 0.543 & 0.539 & 0.00 & $P<0.001$ \\
\hline $\begin{array}{l}\text { Human needs } \\
\text { assistance }\end{array}$ & 0.544 & 0.661 & 0.00 & $P<0.001$ \\
\hline $\begin{array}{l}\text { Existential/ } \\
\text { phenomenological/ } \\
\text { spiritual }\end{array}$ & 0.559 & 0.545 & 0.00 & $P<0.001$ \\
\hline
\end{tabular}

Table 2 presents the level of the quality of nursing care provided by the community health nurses. The result revealed that the skills and competence was very good. On the other hand, the coordination of care after treatment rated as the lowest which is interpreted as fair. The average mean was interpreted as good.

\section{DISCUSSION}

Caring is a term that has attracted a great deal of interest in modern nursing literature, where it has become the center of nursing and other medical care. Many experts said that caring is the central, dominant and unifying feature of nursing. A growing understanding of this concept is beginning to influence nursing theory, research, education, and practice.

According to Leyson (1996) care is the nursepatient relationship that is best conveyed interpersonally and has done wonders in maintaining the life of the patient. Nurses deal with different patients every day and that means they constantly need to reach their patient's needs and expectation. The nature, heart, and concentration of nursing practice has been called caring. The different aspects of the caring behavior among community health nurses based on the survey made. The data are reflected on the following table:

The results of the present study corroborated with the study conducted in a tertiary hospital in the 
Philippines wherein all the caring factors mentioned were mostly practiced by the staff nurses (Fortuno, Oco, \& Clores, 2017). Likewise, the study conducted in Finland yielded same results (Charalambous et al., 2010).

The result is an indication that there are still room for improvement in as far as the quality of care delivered by the community health nurses. This indicates that the Municipal Health Offices and the Nursing Managers need to design strategies and activities in order to maximize potential of the nurses in their capacity to deliver quality nursing care. On the other hand, this calls for the intensification of the human resource development in the Health Department as the main agency.

Table 3 presents the predictive analysis using linear regression. The result revealed that in all instance the " $P$ " value is 0 suggesting high significance. The R2 values in each case reveals that more than $30 \%$ of the deviation from the criterion variable's mean can be explained by the predictor variables. Based on the contention by Pallant (2010) it was observed that the Beta values are more than 0.5 in each case and that supports a positive correlation, predicting that the higher the predictor values.

Furthermore, the result is a reflection that every aspect of how the nurses deal with the clients/patients in the community affects the way and manner they care. This further means that the totality of the personality of any person giving care and rending health services affects the quality of care they deliver.

The regression analysis commends and supports greatly to the findings of Fingeld-Connet (2013) developed approaches for improving healthcare behaviors and quality management which in this study is represented by the seven aspects of the caring behaviors. The significant identification of the caring behaviors as predictors of the quality of care are reflective of the needed standard of behavior needed by the community health nurses in the delivery of the care to their constituents

\section{CONCLUSION}

This study revealed that the majority of the community health nurses assigned in the barangay health centers in the Municipality of Naval mostly practiced the 7 criteria of caring behaviors such as humanism/faith/hope/sensitivity, helping/trust, expression of positive or negative feelings, teaching/ learning,supportive/protective/corrective environment, human needs assistance, existential/phenomenological /spiritual. Moreover, a good level of quality nursing care was was also reported and that the seven criteria of caring behaviors strongly predict the quality of nursing care given by community health nurses. This implies that the community health nurses have a positive caring behavior towards their patients which led to a good quality nursing care. However, there were some criteria in the quality nursing care where in it was rated fair such as answering calls, restful atmosphere provided and coordination of care. Therefore, prompt management and treatment are deemed necessary in order to improve the quality of nursing care rendered among the patients. The researcher recommends the development of an enhanced nursing care plan that can be utilized by the community health nurses, and it will serve as a guide in dealing with the patients, thus improving the quality of nursing care.

\section{Conflict of Interests}

The authors declare that they have no conflict of interests.

\section{ACKNOWLEDGEMENT}

The authors would like to express their sincerest gratitude to the Biliran Province State University Administration and to the Municipal health officer of Naval, Biliran for the support given during the conduct of the study. Likewise, to all the community health nurses who were selected as the research respondents for their cooperation in answering the questionnaires.

\section{REFERENCES}

Appleton, C. (1993). The Art of Nursing: The Experience of Patients and Nurses. Journal of Advanced Nursing, 18(6), 892-899.

Charalambous, A., Katajisto, J., Valimaki, M., Leino-Kilpi, H., \& Suhonen, R. (2010). Individualized Care and the 
Professional Practice Environment: Nurses' Perceptions. International Nursing Review, 57(4), 500-507.

Cronin, S., \& Harrison, B. (1988). Importance of Nurse Caring Behaviors as Perceived by Patients After Myocardial Infarction. Heart Lung, 17(4), 374-380.

Fingeld-Connet, D. (2013). Meta-synthesis of Caring in Nursing. Journal of Advanced Nursing, 17(2), 196-204

Fortuno, A., Oco, D., \& Clores, M. (2017). Influential Components of Caring Nurse-Patient Interaction (CNPI) in a Tertiary Hospital in the Philippines: Towards Improving Health Outcomes of Patients. International Journal of Nursing Science, 7(4), 84-90.

Karlsson, M., \& Pennbrant, S. (2020). Ideas of Caring in Nursing Practice. Nursing Philosophy, 21(4), 1-5.

Laschinger, H.S., Hall, L.M., Pedersen, C., \& Almost, J. (2005). A Psychometric Analysis of the Patient Satisfaction with Nursing Care Quality Questionnaire. Journal of Nursing Care Quality, 20(3), 220-230.

Leyson, A. (1996). A Descriptive Analysis of Caring Behavior of Nurses in Culion Sanitarium. Philippine Womens University Research Journal, 1, 106-111.

Pallant, J. (2010). SPSS Survival Manual: A Step by Step Guide to Data Analysis using SPSS. Maidenhead: Open University Press/McGraw-Hill. https://searchworks.stanford.edu/view/8839418

Poortaghi, S., Ebadi, A., Salsali, M., Raiesifar, A., Davoudi, N., \& Pourgholamamiji, N. (2019). Significant Influencing Factors and Practical Solutions in Improvement of Clinical Nursing Services: A Delphi Study. Biomed Central Health Services Research, 20(1).

Roach, S. (2002). Caring: The Human Mode of Being: A Blueprint for the Health Professions ( $2^{\text {nd }}$ Revised Edition). Canadian Healthcare Association Press.

Sibiya, M. N. (2018). Effective communication in nursing. Nursing, 19. 